\title{
Hesperidin Increase Cytotoxic Activity of Doxorubicin on Hela Cell Line Through Cell Cycle Modulation and Apoptotis Induction
}

\author{
Indri Kusharyanti ${ }^{1}$ Larasati $^{2}$, Ratna Asmah Susidarti ${ }^{2}$, Edy Meiyanto ${ }^{2 *}$ \\ ${ }^{1}$ Program Studi Farmasi, Fakultas Kedokteran dan Ilmu Kesehatan, Universitas Tanjungpura Pontianak \\ ${ }^{2}$ Cancer Chemoprevention Research Center, Faculty of Pharmacy \\ Universitas Gadjah Mada,Yogyakarta \\ Jalan Sekip Utara 555281 (Telp. 02746492662 Fax. 543120)
}

\begin{abstract}
Combination of chemotherapeutic agent and chemopreventive agent is being a new approach in cancer treatment. This is aimed at enhancing the effectivity and also reducing drug resistance and adverse side effect of the chemotherapeutic agent. Hesperidin, a citrus flavonoid has reported to reduce the proliferation of many cancer cells. The objectives of this study were to investigate cytotoxic activities, cell cycle modulation and apoptosis induction of hesperidin and its combination with doxorubicin on Hela cell lines. MTT [3-(4,5-dimethylthiazol-2-yl)-2.5diphenyltetrazolium bromide] assay was used to measure the growth inhibitory effect of hesperidin and its combination with doxorubicin on Hela cells. Cell cycle profile was determined by flowcytometry and the data obtained was analyzed by using ModFit LT 3.0 program. Apoptosis assay was done using double staining method using ethidium-bromide and acridine-orange. Hesperidin inhibited cell growth with $\mathrm{IC}_{50} 48 \mu \mathrm{M}$, while the $\mathrm{IC}_{50}$ of doxorubicin was $1000 \mathrm{nM}$. Combination of $500 \mathrm{nM}$ doxorubicin and $6 \mu \mathrm{M}$ hesperidin showed strongest inhibitory effect toward Hela cells. Hesperidin of $24 \mu \mathrm{M}$ accumulated HeLa cells at GI phase, but its combination with $500 \mathrm{nM}$ Doxorubicin gave $\mathrm{Gl}$ and $\mathrm{S}$ phase accumulation at $24 \mathrm{~h}$ incubation. Both of Hesperidin and Doxorubicin were capable of inducing apoptosis. In accordance of the apoptotic effect, hesperidin, doxorubicin and their combination decreased the expression $\mathrm{Bcl}-2$ and increased the expression of Bax. According to this result, hesperidin has a potency to be developed as co-chemotherapeutic agent for cervical cancer.
\end{abstract}

Keywords: Cochemotherapy, Hesperidin, Doxorubicin, Hela, MTT assay

\section{INTRODUCTION}

Increasing the efficacy of chemotherapeutic agent could be achieved by combination with chemopreventive agent so that the effect will be better than it single treatment. Hesperidin, a citrus bioflavonoid showed strong toxic effect in Caco-2, CEM/ADR5000 and CCRF-CEM cancer cell lines with dengan IC 50 195, 230 dan $95 \mu \mathrm{M}$ respectively (El-Readi et al., 2009). Hesperidin also showed antiproliferative effect in MCF-7 cells transfected with green fluoresens protein (GFP)/alpha-tubulin (MCF-7-GFP-Tubulin) (Lee et al., 2009). It is also reported that hesperidin protective effect in benzo[a]pirene induced testicular toxicity paradigm and repaired the function of lactate dehydrogenase (LDH-X), superoxide dismutase (SOD), dan glutathione-Stransferase (GST) enzyme (Arafa et al., 2009). Previous study has reported that Hesperidin could induce apoptosis in human colon cancer cells through CASP3 activation. Hesperidin downregulated the protein expression of pro-CASP3, and upregulated the level of active CASP3 (Park et $a l, 2008)$.

It is suggested, based on above studies, that Hesperidin has a potency to be combined with chemotherapeutic agent (cochemotherapy) in treating human cancer cells. Worldwide, cervical cancer is the $5^{\text {th }}$ most common cancer in women with approximately 471,000 new cases diagnosed each year. The Caribbean, other parts of Africa, South America and South Eastern Asia have very high incidences of this disease (CC, 2010). Cancer therapy is usually done with chemotherapeutic agents, but they have many side effect and resistance.

*Corresponding author email : meiyan_e@ugm.ac.id 
One of them is doxorubicin. Cardiotoxicity is a well-known side effect of doxorubicin and is frequently a dose-limiting factor. The reduction in dose limiting side effects, therefore, represents a major challenge in improving the clinical application of these agents. This research is aimed to assess whether combination of Hesperidin with Doxorubicin (as model of chemotherapeutic agent) have synergistic effect and induce apoptosis on human cervical cancer Hela cells.

\section{MATERIALS AND METHODS}

\section{Cell culture}

Cervical carcinoma cell line (HeLa) were obtained from Cancer Chemoprevention Research Centre, Faculty of Pharmacy, Gadjah Mada University. Cell lines were grown in Dulbecco's modified Eagles medium (DMEM) with $10 \%$ Fetal Bovine Serum (Gibco) and 1\% PenicillinStreptomycin (Gibco) at $37^{\circ} \mathrm{C}$ in a humidified atmosphere of $5 \% \mathrm{CO}_{2} / 95 \%$ air.

\section{Cytotoxicity assay}

Cytotoxicity experiments were performed using MTT assay. Hela Cells were seeded at a density of $5 \times 10^{3}$ cells/well and allowed to attach for $24 \mathrm{~h}$. One day after initial seeding, cells were treated with either various concentrations of Hesperidin (Sigma) alone Doxorubicin (Ebewe) alone and their combination. After $24 \mathrm{~h}$ culture medium was removed and cells were washed in PBS (Sigma). Then, cells were incubated with 100 $\mu \mathrm{L}$ culture medium and $10 \mu \mathrm{L}$ MTT (Sigma) 5 $\mathrm{mg} / \mathrm{mL}$ in each well for 4-6 h. Stopper reagent was added after formazan formation prior to MTT reduction. The absorbance of each well was measured using ELISA reader at $595 \mathrm{~nm}$ (Bio$\mathrm{Rad})$. The $\mathrm{IC}_{50}$ was determined using Excell MS Office 2007 and probit analysis (SPSS 11.5).

\section{Apoptosis Detection}

Apoptosis was detected using acrydine orange-ethidium bromide staining $(\mathrm{AO} / \mathrm{EB}$ double staining). Hela cells $\left(5 \times 10^{4}\right.$ cells/well) were seeded on coverslips in 24-well plates until 50-60\% confluent. Cells were then incubated with Hesperidin alone, Doxorubicin alone and their combination for $24 \mathrm{~h}$. Culture medium was removed and cells were washed with PBS. Coverslips were placed into object-glass and added with $10 \mu \mathrm{L} 1 \mathrm{X}$ working solution acrydine orange (Sigma) - ethidium bromide (Sigma), observed using fluoroscence microscopy (Zeiss MC 80). Apoptotic cells which had lost their membrane integrity appeared orange and showed morphological features of apoptosis. Cells were identified as apoptotic on the basis of specific morphological criteria, including condensation and fragmentation of chromatin, and formation of apoptotic bodies.

\section{Cell Cycle Analysis}

Hela cells were seeded at $5 \times 10^{5}$ cells/well on six wells tissue culture plate. After 24 hours incubation cells were treated with Hesperidin (12 $\mu \mathrm{M}$ or $24 \mu \mathrm{M})$ alone or its combination with doxorubicin $(500 \mathrm{nM})$. After $24 \mathrm{~h}$ of these treatments, cells were trypsinized and cells pellets were collected. Cells were trypsinized, spin at 2000 rpm for 3 minutes and washed twice with cold PBS. Cells were resuspended in propidium iodide solution $(50 \mu \mathrm{g} / \mathrm{ml}$ in PBS contained $1 \%$ triton $\mathrm{X}$ $100)$ and then treated with RNAse DNAse free (20 $\mu \mathrm{g} / \mathrm{ml}$ ) for 10 minutes at $37^{0} \mathrm{C}$. The treated cells then subjected to FACS flowcytometry and data was analyzed by using ModFit LT 3.0 program.

\section{Immunocytochemistry}

Cells were plated at $5 \times 10^{4}$ cells/well and cultured in 24-wells plate at cover slip until $80 \%$ confluent. At time 0 , medium was replaced by fresh complete medium with hesperidin $24 \mu \mathrm{M}$ and doxorubicin $500 \mathrm{nM}$ and incubated in CO-2 5\% incubator at $37^{\circ} \mathrm{C}$ for 18 hours. Then, cells were harvested and were washed with PBS and fixed with cold methanol for $10 \mathrm{~min}$ at freezer $-4^{0} \mathrm{C}$. Cells washed, and blocked in hydrogen peroxide blocking solution for 10 minutes at room temperature. After that, cells washed with PBS and incubated with prediluted blocking serum for 10 minutes at room temperature. Cells were stained for $1 \mathrm{~h}$ at room temperature with primary $\mathrm{Ab}(\mathrm{Bcl}-$ 2 and Bax). After washing three times in PBS, secondary antibody were applied for $15-30 \mathrm{~min}, 1$ : 2 in PBS and added 5\% AB serum then washed with PBS three times. The slide was incubated with streptavidin-biotin-complex for $15 \mathrm{~min}, 1: 2$ in PBS and added 5\% AB serum and washed three times in PBS. Slides were incubated in DAB (3,3 diaminobenzidin) solution for 3-8 min and washed with aquadest. Cells were counterstained for 3-4 min with Mayer-Haematoksilin. After incubation, coverslip washed with aquadest and then immersed with xylol and alcohol. Protein expression was assessed under light microscope. Positive expression will give a dark brown colour in nucleus and cells with no expreesion will give purple. 


\section{RESULTS AND DISCUSSION}

\section{Effect of Hesperidin and Doxorubicin on cell growth}

Cell viability assay was done to determine the inhibitory concentration $\left(\mathrm{IC}_{50}\right)$ of Hesperidin alone, Doxorubicin alone and their combination on Hela cells. All of these compounds showed growth
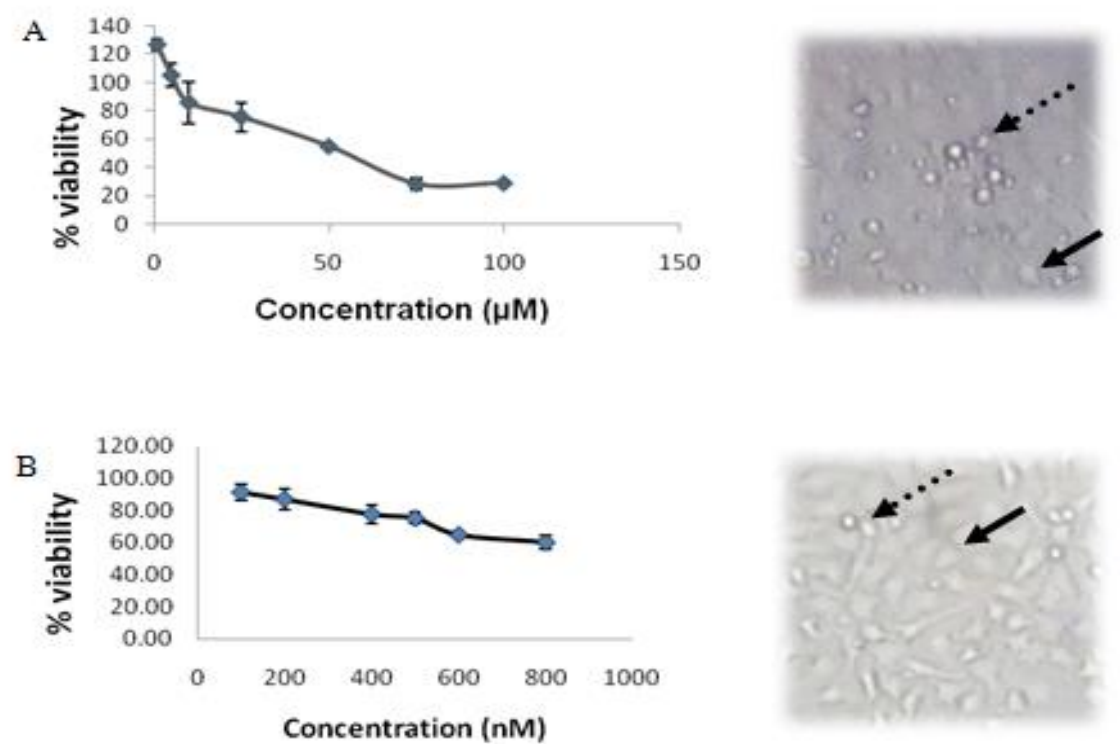

C

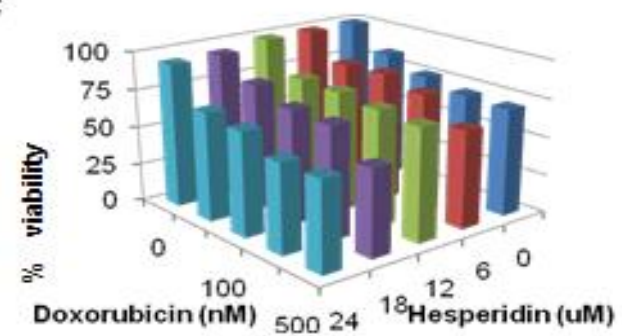

inhibitory effect in dose dependent manner. Hesperidin and Doxorubicin had the $\mathrm{IC}_{50}$ values of $48 \mu \mathrm{M}$ and $1 \mu \mathrm{M}$, respectively. Combination of Hesperidin and Doxorubicin decreased viability cells more than Doxorubicin alone (Fig.1). The lowest viability $(58,05 \%)$ showed by combination of $24 \mu \mathrm{M}$ Hesperidin, and $500 \mathrm{nM}$ Doxorubicin.

Figure I. Cell viability assay of (A) Hesperidin, (B) Doxorubicin (C) Combination of Hesperidin and Doxorubicin in Hela cells. Result showed that Hesperidin and Doxorubicin had the IC 50 values of 48 $\mu \mathrm{M}$ and $1000 \mathrm{nM}$, respectively. Every dot is means from 3 replication. Cells photo $100 x$ magnification. $\rightarrow$ viable cells, $\cdots$ cells with morphological changes.

\section{Effect of Hesperidin and Doxorubicin on apoptosis}

Both of Hesperidin and Doxorubicin were capable of inducing apoptosis at inhibitory concentration (Fig. 2). The green fluorescence indicates the viable cells while the orange-red fluorescence indicates the death cells. Apoptotic cells show the occurrence of chromatin condensation and the orange-red apoptotic bodies. Combination of Hesperidin and Doxorubicin appeared to have the strongest apoptotic effect. 


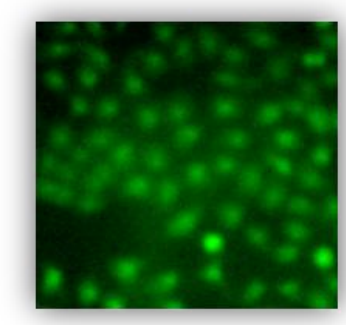

A

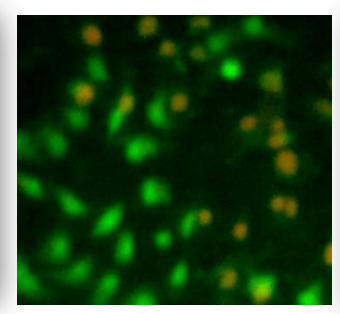

B

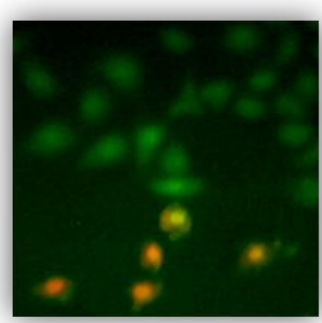

C

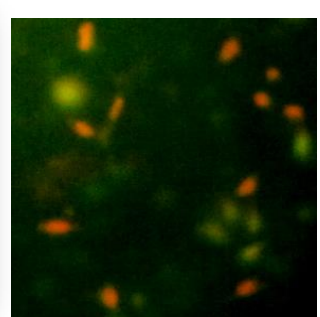

D

Figure 2. Apoptosis induction of Hesperidin and Doxorubicin in Hela cells. (A) control cells, (B), (C), and (D) cell treated with $24 \mu \mathrm{M}$ Hesperidin, $500 \mathrm{nM}$ Doxorubicin, and combination of $24 \mu \mathrm{M}$ Hesperidin- $500 \mathrm{nM}$ Doxorubicin at incubation time $24 \mathrm{~h}$. Cells was stained with acrydine orangeethidium bromide and saw in fluorosence microscope. 100x magnification. $\rightarrow$ viable cells

\section{Effect Hesperidin and Doxorubicin on cell} cycle progression of cancer cell

Flowcytometric analysis was used to observed the distribution of cell population on cell cycle. As shown in Fig. 3, there was an accumulation at G1 phase of Hela cells treated with $24 \mu \mathrm{M}$ Hesperidin. But treatment with 500 $\mathrm{nM}$ Doxorubicin, and combination of $24 \mu \mathrm{M}$ Hesperidin- $500 \mathrm{nM}$ Doxorubicin showed accumulation at $\mathrm{S}$ phase at incubation time $24 \mathrm{~h}$.
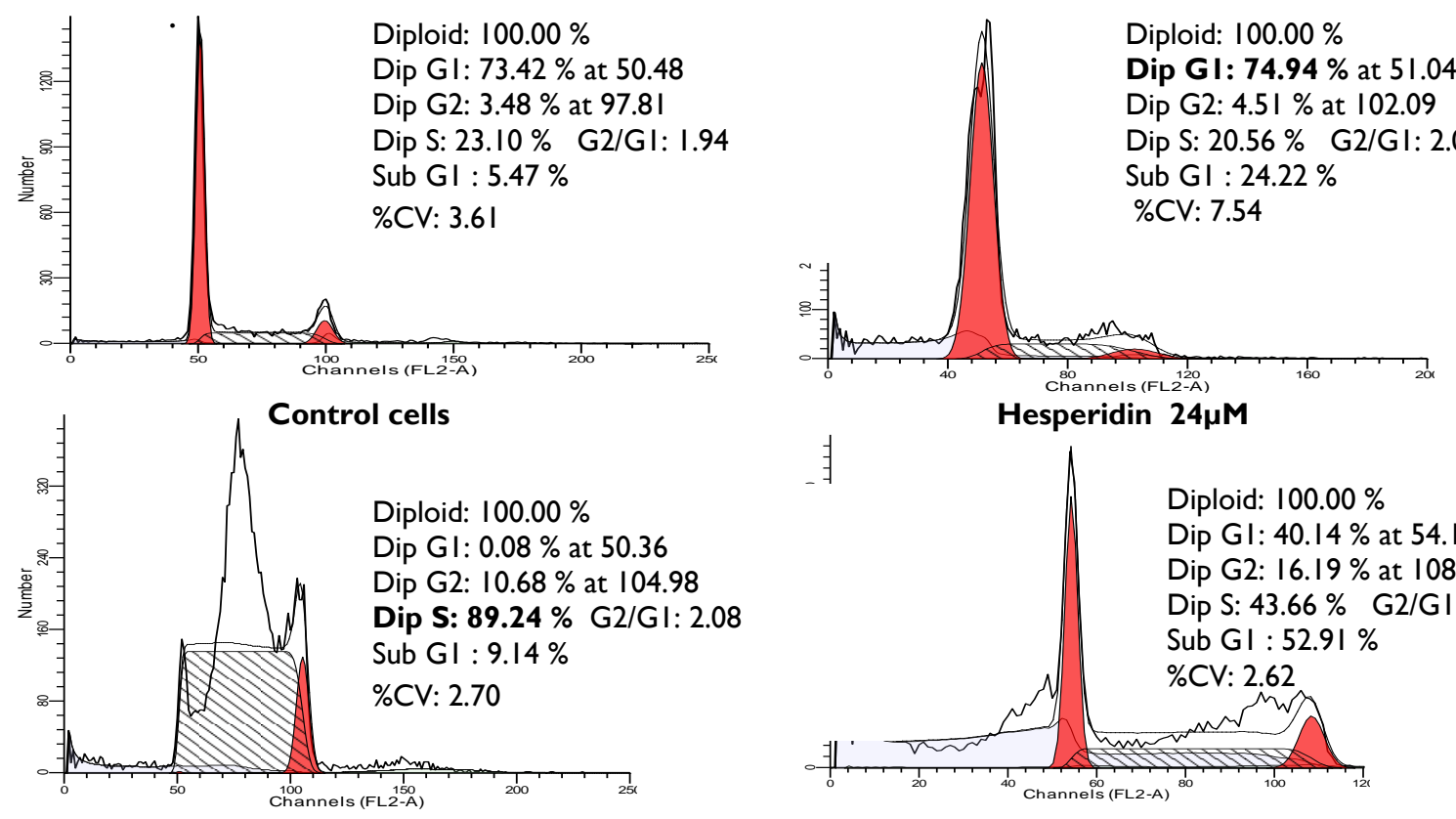

Hesperidin $24 \mu \mathrm{M}$

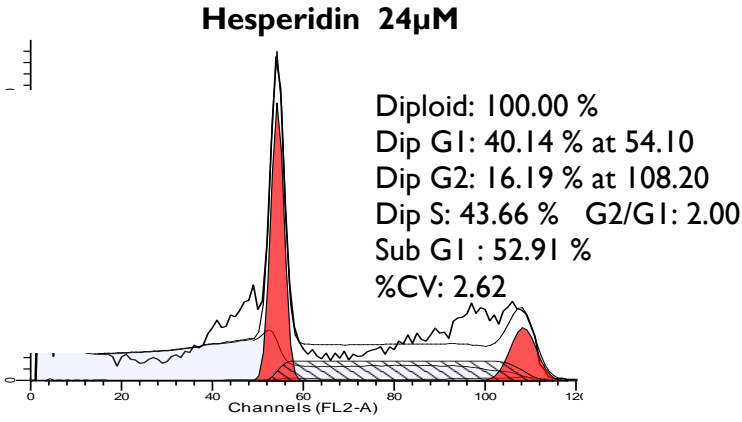

Hesperidin-Doxorubicin $24 \mu \mathrm{M}-500 \mathrm{nM}$

Figure 3. Flowcytometric analysis. Cells were treated with $24 \mu \mathrm{M}$ Hesperidin, $500 \mathrm{nM}$ Doxorubicin, and combination of $24 \mu \mathrm{M}$ Hesperidin- $500 \mathrm{nM}$ Doxorubicin at incubation time $24 \mathrm{~h}$, and stained with propidium iodide.

Effect Hesperidin and Doxorubicin on Bcl-2 and Bax Expression on HeLa cell lines

To confirm the mechanism of hesperidin and its combination with doxorubicin induced apoptosis, this research observed the effect of hesperidin, doxorubicin and their combination on the expression of $\mathrm{Bax}$, and $\mathrm{Bcl}-2$ by using immunocytochemistry method. Interestingly, the expression of $\mathrm{Bcl}-2$ on the hesperidin and doxorubicin treated cells was decreased compare to the control cells but the decreasing level of Bcl-2 expression on the combination treated cells was higher than on the hesperidin and doxorubicin single treated cells (Fig. 4). Moreover, the increasing level of Bax expression on the both single and combination treated cells not significantly different, but still higher than the control cells (Fig. 4). These data show that the combination more potent to induce apoptosis on the HeLa cells than single treatment. 


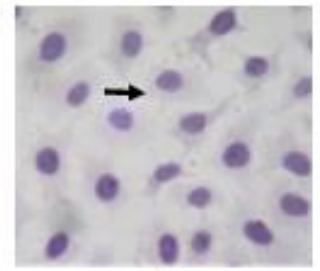

A

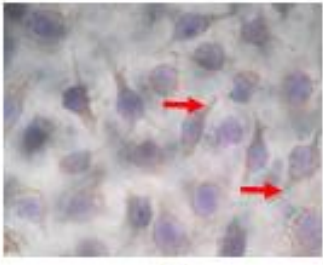

B

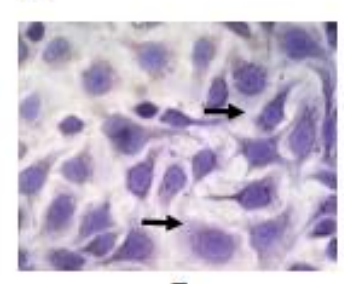

E

D

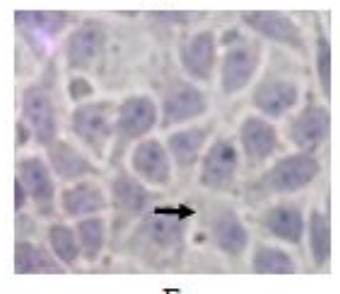

F

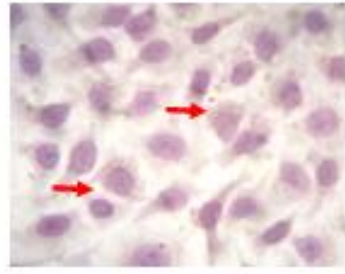

G

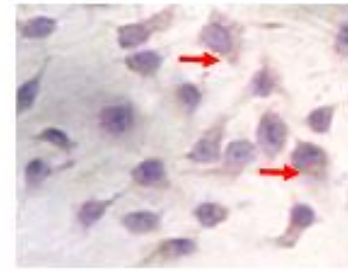

$\mathrm{H}$

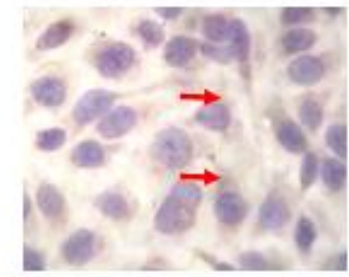

I

Fig 4. Protein involves in apoptotic process on HeLa cells examined by immunocytochemistry methods (A) Control cells without antibody (B) Control cells with Bcl-2 Ab (C) Doxorubicin 500nM with Bcl-2 Ab (D) Hesperidin $24 \mu \mathrm{M}$ with Bcl-2 Ab (E) Doxorubicin 500nM-Hesperidin $24 \mu \mathrm{M}$ with Bcl-2 Ab (F) Control cells with Bax Ab (G) Doxorubicin 500nM with Bax Ab (H) Hesperidin $24 \mu M$ with Bax Ab (I) Doxorubicin 500nM-Hesperidin $24 \mu \mathrm{M}$ with Bax Ab. This experiment used DAB as the chromogen, dark brown staining in nucleus indicated the positive expression $(\rightarrow)$, cells were counterstained with H\&E showed purple color indicated negative expression $(\rightarrow$ ) of the protein.

The results of this study demonstrate the ability of hesperidin as an anti-cancer which has the potency of inhibiting cell proliferation. Cytotoxic properties can be associated with the ability to spur occurrence of cell cycle arrest or accelerate apoptosis in cells. Our data found that hesperidin induce cell cycle arrest in G1 phase. But when hesperidin combined with doxorubicin, its induced both cell cycle arrest in G1 and S phase. So maybe doxorubicin and hesperidin have different mechanism that cause cell cycle arrest and this bring a synergistic effect. The occurrence of cell cycle arrest may be through different mechanisms involving various proteins. Protein p21 and p27 is a member of Cip / Kip proteins can form a trimer with cyc D-CDK complexes (holoenzim). Trimer with holoenzim will result holoenzim can not phosphorylate $\mathrm{pRB}$, so the cells will arrest in G1. Protein p53 is regulator that can stimulate expression of $\mathrm{p} 21$, which can cause cell cycle arrest in G1 phase (Andrei, 2002). In HeLa cells, p53 protein was already degraded by E6 is expressed by the HVP. So that maybe hesperidin can stabilized or even increase p53 levels.

This present study showed that hesperidin, doxorubicin and their combination induced apoptosis in HeLa. Apoptosis can occur through various mechanisms. NF- $\kappa \mathrm{B}$ proteins can inhibit apoptosis through increased transcription of $\mathrm{Bcl}-2$ that works to prevent the release of cytochrome $\mathrm{c}$ in mitochondria by Bax (Simstein et al., 2003). The inhibition of NF-kB also causes decreasing of Bcl-2 and Bcl-xL expression, two main antiapoptotic proteins. Hesperidin inhibit Bcl-2 
expression in colon cancer cells (Park et al., 2008). Hesperidin and doxorubicin show decreasing of Bcl-2 level on HeLa. Hesperidin suppressed TPAstimulated NF- $\mathrm{kB}$ translocation into the nucleus through IкB inhibitory signaling pathways and also inhibited TPA-induced AP-1 activity by the inhibitory phosphorylation of p38 kinase and c-Jun N-terminal kinase (JNK) signaling pathways (Lee et al, 2010) and inhibition of PI3K path that eventually spur apoptosis through inhibition of inactivation of $\mathrm{Bad}$ (Gu et al., 2004). Increased apoptosis by the combination of hesperidin and doxorubicin via inhibition of NF- $\mathrm{KB}$ activation can also occur through inhibition of MAP kinase and PI3K path.

The result of this present study showed increasing Bax level significantly due to hesperidin, doxorubicin and their combination induction. These data suggested that the apoptosis may occur by increasing Bax level. Desaintes et al., (1999) proved that, increase of p53 in HeLa cells increases the expression of p21 but not increased expression of Bax. The possibility of apoptosis occurred due to intervention with another pathway beside p53 induction as one of Bax activator. Joubert et al., (2005) reported that there was increasing level of Bax and decreasing level of Bcl-2 in Hela due to prostaglandin $\mathrm{A}_{2}$ and 2methoxyestradiol treatment. Eventhough Bax expression level was positively regulate by $\mathrm{p} 53$, but Bax level remain increasing on p53 mutant cell line like T47D (Butt et al., 2000). So this is indicating that hesperidin could interfere another pathway to increase Bax level. Activation of caspase 8 by formation of DISC activates the downstream caspases through the cleavage of Bid into tBid. This could induce oligomerization of Bax and couse apoptosis (Rastogi et al., 2009). But to prove this suggestion still needed more investigation.

Overall hesperidin can increase the effectiveness of doxorubicin. Despite this need to conduct further research to explore the potential of doxorubicin combined with hesperidin, especially the molecular mechanisms that facilitate increased effect of doxorubicin. In addition, a combination of in vivo testing is needed in order to develop hesperidin as an cochemotherapy agent.

\section{CONCLUSION}

Hesperidin has cytotoxic effect on Hela cells with $\mathrm{IC}_{50} 48 \mu \mathrm{M}$. Co-chemotherapy application of doxorubicin -hesperidin on Hela cells showed synergism effect through cell cycle modulation and apoptosis induction.

\section{REFERENCES}

Andrei L.G. and Angela L.T., 2002, The Role of the Cyclin-dependent Kinase Inhibitor p2I in Apoptosis I, Molecular Cancer Therapeutics, I, 639-649.

Arafa, H., Aly, H., Abd-Ellah, M. and El-Refaey, H., 2009, Hesperidin Attenuates Benzo[a]pyrene-Induced Testicular Toxicity in Rats Via Regulation of Oxidant/Antioxidant Balance, Toxicol Ind Health, 6, 4I7-427.

Butt, A.J., Firth, S.M., King, M.A. and Baxter, R.C., 2000, Insulin-Like Growth Factor-Binding Protein-3 Modulates Expression of Bax and $\mathrm{Bcl}-2$ and Potentiates P53Independent Radiation-Induced Apoptosis In Human Breast Cancer Cells, J. Biol Chem, 275(50), 39174-39181.

CC, 2010, Cervical Cancer, Available at: www. CervicalCancer.org/ Accessed 20 September 2009.

Desaintes, C., Goyat, S., Garbay, S., Yaniv, M. and Thierry, F., 1999, Papillomavirus E2Induces p53-independent Apoptosis in HeLa Cell, Oncogene, 18, 4583-4545.

El-Readi, M.Z., Hamdan, D., Farrag, N., El-Shazly, A. and Wink, M., 2009, Inhibition of Pglycoprotein Activity by Limonin and Other Secondary Metabolites from Citrus Species in Human Colon and Leukaemia Cell Lines, Eur. J. Pharmacol., 626(2-3), 139-145.

Gu, Q., Wang, D., Wang, X., Peng, R., Liu, J., Jiang, T., Wang, Z., Wang, S. and Deng, H., 2004, Basic fibroblast growth factor inhibits radiation-induced apoptosis of HUVECs. I. The PI3K/AKT pathway and induction of phosphorylation of BAD, Radiat Res., I6I, 692-702.

Joubert, A., Maritz, C. and Joubert, F., 2005, Influence of prostaglandin $A_{2}$ and 2methoxyestradiol on $\mathrm{Bax}$ and $\mathrm{Bcl}-2$ expression levels in cervical carcinoma cells, Biomedical Research, 26(2), 87-90.

Lee, S.H., Soung, Y.H., Lee, J.W., Kim, H.S., Lee, J.H., Park, J.Y., Cho, Y.G., Kim, C.J., Kim, S.Y., Park, W.S., Kim, S.H., Lee, J.Y., and Yoo, N.J., 2003, Mutational Analysis Of Noxa Gene In Human Cancers, APMIS, I I I, 599-604.

Lee, C.J., Wilson, L., Jordan, M.A., Nguyen, V., Tang, J., and Smiyun, G., 2009, Hesperidin Suppressed Proliferations of Both Human Breast Cancer and Androgen-dependent 


\section{[iscc. IIJ]ClC}

Prostate Cancer Cells, Phytother Res., In Press

Hua, L.K., Yeh, M.H., Kao, S.T., Hung, C.M., Liu, C.J., Huang, Y.Y. and Yeh, C.C., 20I0, The inhibitory effect of hesperidin on tumor cell invasiveness occurs via suppression of activator protein $I$ and nuclear factorkappaB in human hepatocellular carcinoma cells, Toxicology Letters, 194(I2), $42-49$.

Nakamura, Y., 2004, Isolation of p53-target genes and their functional analysis, Cancer Sci, 95(I), 7-II.
Park, H.J., Kim, M.J., Ha, E. and Chung, J.H., 2008, Apoptotic Effect of Hesperidin through Caspase3 Activation in Human Colon Cancer Cells, SNU-C4, Phytomedecine, I5, $|47-| 5 \mid$.

Rastogi, R.P., Richa, and Sinha, R.P., Apoptosis: Molecular Mechanisms and Pathogenicity, EXCLI Journal, 8, I55-I8I.

Simstein, R., Burow, M., Parker A., Weldon, C., and Beckman, B., 2003, Apoptosis, Chemoresistance, and Breast Cancer: Insights from the MCF-7 Cell Model System, Exp Biol Med., 228, 995-1003. 